\title{
Blogueiros fitness no Instagram: o corpo e o merchandising editorial de suplementos alimentares
}

\author{
Fitness bloggers on Instagram: the body and the product placement of \\ dietary supplements
}

\section{Fitness bloggers en el Instagram: el cuerpo y el emplaziamento publicitario de suplementos alimenticios}

\author{
Graciele Stolarski ${ }^{1, a}$ \\ grastolarski@gmail.com | https://orcid.org/oooo-0003-0988-1679 \\ Tiago Franklin Rodrigues Lucena ${ }^{2, b}$ \\ tiagofranklin@gmail.com | https://orcid.org/o000-0002-0154-7417 \\ Rute Grossi Milani ${ }^{2, c}$ \\ rute.milani@unicesumar.edu.br | http://orcid.org/oooo-0o03-2918-1266 \\ Leonardo Pestillo de Oliveira ${ }^{2, d}$ \\ leopestillo@gmail.com | https://orcid.org/o000-0001-5278-0676 \\ ${ }^{1}$ Educação Básica no Município de Marechal Cândido Rondon. Marechal Cândido Rondon, PR, Brasil. \\ ${ }^{2}$ Centro Universitário Cesumar, Instituto Cesumar de Ciência, Tecnologia e Inovação. Maringá, PR, Brasil. \\ a Mestrado em Promoção de Saúde pelo Centro Universitário de Maringá. \\ b Doutorado em Artes pela Universidade de Brasília. \\ c Doutorado em Medicina pela Universidade de São Paulo. \\ d Doutorado em Psicologia Social pela Pontifícia Universidade Católica de São Paulo.
}

\section{Resumo}

O Instagram é uma rede social online que permite a criação, manipulação e compartilhamento de fotografias ou vídeos. Com o objetivo de classificar e analisar o conteúdo postado pelos perfis fitness populares no Brasil, selecionaram-se dez contas públicas a serem seguidas ao longo de quinze dias em 2016. Duas categorias temáticas obtiveram destaque: a) presença de merchandising editorial de suplementos alimentares e b) divulgação de serviços de profissionais da estética ou da saúde. As postagens reforçam o ideal de beleza presente na mídia de massa, há alta frequência de postagem, principalmente com fotos do corpo ou de partes dele e as produções das fotografias são profissionais, com poucas selfies. O que oportuniza o uso das redes sociais como espaços para futuras ações e intervenções de promoção da saúde, por parte de agências e conselhos de profissões.

Palavras-chave: Redes sociais; Instagram; Fitness; Fotografia; Promoção da saúde. 


\begin{abstract}
Instagram is an Online Social Network-OSN that allows the creation, edition and sharing of photos or videos. With the aim to classify and analyze the content posted by popular fitness profiles in Brazil, ten public accounts were selected to follow them over a period of 15 days in 2016. Two thematic categories were highlighted: a) the product placement of dietary supplements; b) shared information about the services of aesthetics or health professionals. The posts reinforce the ideal of beauty present in mass media, there is high frequency of posting, especially with highly professional photos of the body or parts of it, and few selfies. Thus they allow the use of social networks as spaces for future actions and health promotion interventions, by health agencies and professional councils.
\end{abstract}

Keywords: Social networks; Instagram; Fitness; Photography; Health promotion.

\title{
Resumen
}

Instagram es una red social que permite crear, manipular y compartir fotografías o vídeos. Con el objetivo de clasificar y analizar el contenido publicado por los perfiles fitness populares en Brasil, se seleccionaron diez cuentas públicas para seguir a lo largo de quince días en 2016. Dos categorías temáticas obtuvieron destaque: a) la presencia de merchandising de suplementos alimenticios; y b) divulgación de servicios de profesionales de la estética o de la salud. Las imágenes refuerzan el ideal de belleza presente en los medios de comunicación de masas, hay alta frecuencia de envío cruzado, principalmente con fotos del cuerpo o de partes de ello. Las producciones de las fotografías son bastante profesionales, con pocas selfies, lo que hace posible el uso de las redes sociales como espacios para futuras acciones y intervenciones de promoción de la salud, por parte de agencias y consejos de profesiones.

Palabras clave: Redes sociales; Instagram; Fitness; Fotografia; Promoción de la salud.

\begin{abstract}
Contribuição dos autores:
Concepção e desenho do estudo: Tiago Franklin Rodrigues Lucena e Graciele Stolarski.

Aquisição, análise ou interpretação dos dados: Graciele Stolarski e Rute Grossi Milani.

Redação do manuscrito: Graciele Stolarski e Tiago Franklin Rodrigues Lucena.

Revisão crítica do conteúdo intelectual: Leonardo Pestillo de Oliveira.
\end{abstract}

Declaração de conflito de interesses: Este trabalho não apresenta conflito de interesses.

Fontes de financiamento: Não houve.

Considerações éticas: Não há.

Agradecimentos/Contribuições adicionais: Ao Prof. Dr. Roberto Pereira (UFPR) do campo da Interação Humano-Computador por orientações conceituais gerais sobre dados de Redes Sociais Online.

Histórico do artigo: Submetido: 02.jan.2018 | Aceito: 15.ago.2018 | Publicado: 21.dez.2018.

Apresentação anterior: Não houve.

Licença CC BY-NC atribuição não comercial. Com essa licença é permitido acessar, baixar (download), copiar, imprimir, compartilhar, reutilizar e distribuir os artigos, desde que para uso não comercial e com a citação da fonte, conferindo os devidos créditos de autoria e menção à Reciis. Nesses casos, nenhuma permissão é necessária por parte dos autores ou dos editores. 


\section{Introdução}

Os smartphones são uma das principais formas de acesso à rede de informação e sua onipresença o torna parte integral da vida cotidiana. Esses dispositivos funcionam com sistemas operacionais (Android, IOS e Windows Phone) e possuem softwares chamados de aplicativos ou apps.

Entre os aplicativos mais populares está o Instagram, como o $4^{0}$ mais baixado no Brasil em $2015^{1}$. Lançado no ano de 2010 para tirar fotos e compartilhá-las, o app é gratuito e uma de suas funções é aplicar filtros na imagem para deixá-las com o efeito visual desejado. Ele é um dos melhores representantes de uma cultura visual e da tendência de redes sociais online (RSO) baseadas em compartilhamento de imagem e vídeos $^{2}$. O interesse em comum entre os usuários no Instagram não é somente a fotografia, mas também o compartilhamento de uma relação de confiança que vai sendo criada a partir das conexões estabelecidas, tais como: 'seguir' o usuário, ser seguido, citar, curtir e comentar nas publicações. Também é possível marcar outros usuários com o uso do sinal @ seguido do nome do perfil desejado - aspecto utilizado para fazer merchandising de produtos ou de outros usuários. Uma de suas funcionalidades é a possibilidade de anexar a conta a outras redes sociais (como Twitter e Facebook), permitindo publicações simultâneas e estendendo o alcance das postagens para pessoas que não participam da rede.

A popularidade do Instagram acrescenta novos exemplos para o debate sobre a exposição da intimidade dos usuários, sobre saúde e as relações de consumo e privacidade na atualidade. Muitos inseridos nessa rede ficam atentos à repercussão da imagem postada, aguardando assim o retorno da "audiência" por meio das opções "curtir" ou "comentar" a foto ${ }^{3}$. Tal exposição das fotografias pressupõe uma espera ou convicção na promessa de ser visto, um dos desejos dos blogueiros fitness.

Ao visitar algumas contas e perfis no Instagram, é possível identificar imagens de corpos fitness e/ou de pessoas realizando exercícios físicos em academias, ao ar livre ou em casa. Embora haja uma diversidade de contas e perfis, o Instagram é popularmente conhecido como uma rede "narcisista", em que a imagem do usuário com corpo, e em lugares interessantes, se destacam ${ }^{4}$. Compartilhar imagens de si, visualizar imagens de outros e a busca por padrões (de beleza e de corpo) vêm preocupando pesquisadores da psicologia, psiquiatria, educação física e nutrição $0^{5,6}$. Tendências marcadas com hashtags como \#thininspiration e \#instafit foram estudadas e identificou-se que a exposição a esse tipo de conteúdo por usuários que se dizem buscar dietas e práticas "saudáveis" pode potencializar estados de bulimia, anorexia e ansiedade . $^{7-9}$ O uso da rede por parte desses blogueiros também vem despertando ações e interesses de conselhos de profissões, como por exemplo o Conselho Federal de Educação Física ${ }^{10}$.

Iniciamos a pesquisa observando os chamados blogueiros fitness brasileiros, que são usuários com interesse em autopromoção e com popularidade pelos seus posts. Considera-se que as RSO ainda apresentam um cenário cheio de incertezas, pessimismos e discussões, mas o universo de imagens de corpos 'perfeitos', a quantidade de seguidores (os chamados usuários que curtem e acompanham essas contas e perfis) e a influência desses blogueiros no cotidiano das pessoas abriram espaço para algumas indagações, em especial: quais são as características gerais das postagens dos principais blogueiros fitness que mereceriam atenção por parte dos profissionais da saúde? Com base nessas reflexões, o artigo busca classificar e analisar o conteúdo postado pelos perfis fitness mais seguidos no Brasil.

\section{Metodologia}

O presente estudo caracterizou-se por realizar uma abordagem qualitativa e exploratória sobre RSO e promoção da saúde (com especial foco na prática de exercícios físicos, exposição do corpo e alimentação saudável) e teve como método o uso da técnica de pesquisa e análise de conteúdo, segundo proposto por Bardin $^{11}$, de posts no aplicativo Instagram. A análise das imagens foi realizada utilizando os softwares Adobe 
Photoshop e Microsoft Picture Manager que permitiram a coleta das imagens (por meio de printscreen e recorte das telas), e a classificação para análise textual e visual da fotografia. A atividade era realizada no período noturno, próximo das 23 h30 para capturar as imagens postadas naquele dia.

Para a seleção da amostra foi identificado o número de dez usuários, previamente escolhidos após observação da frequência de postagens das imagens em contas abertas. As contas pertenciam a blogueiros fitness que possuíssem no mínimo duzentos mil seguidores. A seleção dos nomes foi iniciada com a inserção dos seguintes descritores no site motor de busca Google: 'perfis fitness Brasil', 'Instagram', 'perfis fitness' e 'Instagram Brasil' e 'contas fitness mais seguidas'. A busca orgânica nesse ambiente apresenta, segundo os critérios do buscador, os sites mais 'relevantes'. A adoção dessa estratégia para seleção dos nomes se deu por reconhecer nesses sites um espaço 'curatorial' que seleciona os perfis e os apresenta segundo diferentes critérios. As duas primeiras páginas de sites visitados apresentaram 36 nomes diferentes. O Quadro 1 mostra a listagem dos blogueiros mais citados nos websites.

Quadro 1 - Perfis citados nos blogues, número de citações e de seguidores e aplicação dos critérios de inclusão

(Continua)

\begin{tabular}{|c|c|c|c|c|}
\hline Nome do perfil & $\begin{array}{l}\text { Quantidade } \\
\text { de citações }\end{array}$ & $\begin{array}{l}\text { Quantidade de } \\
\text { seguidores }(26 / 07)\end{array}$ & Critério de exclusão & $\begin{array}{l}\text { Atende } \\
\text { aos } \\
\text { critérios }\end{array}$ \\
\hline JujuSalimeni & $3 x$ & 9,5 milhões & - & $\operatorname{sim}$ \\
\hline Izabel Goulart & $1 \mathrm{x}$ & 3 milhões & $\begin{array}{l}\text { Top model Victoria's } \\
\text { Secret }\end{array}$ & $x$ \\
\hline Gabriela Pugliesi & $6 x$ & 2,6 milhões & - & $\operatorname{sim}$ \\
\hline Bella Falconi & $3 x$ & 2,5 milhões & Nutricionista & $x$ \\
\hline Bianca Anchieta & & 1,1 milhões & Atriz da Rede Globo & $x$ \\
\hline Camila Guper & $2 x$ & $757 \mathrm{mil}$ & - & $\operatorname{sim}$ \\
\hline Kéfera Buchman & $1 x$ & 756 mil & - & $\operatorname{sim}$ \\
\hline Adriana Tyssen & $1 x$ & $712 \mathrm{mil}$ & Estudante de nutrição & $x$ \\
\hline Carol Buffara & $5 x$ & $511 \mathrm{mil}$ & - & $\operatorname{sim}$ \\
\hline Carol Magalhães & $2 x$ & $406 \mathrm{mil}$ & - & $\operatorname{sim}$ \\
\hline Raquel Uzai & $1 x$ & $238 \mathrm{mil}$ & - & $\operatorname{sim}$ \\
\hline Alessandra Luglio & $1 x$ & $120 \mathrm{mil}$ & $\begin{array}{l}\text { Quantidade de } \\
\text { seguidores }<200 \text { mil }\end{array}$ & $\mathrm{x}$ \\
\hline Tati Guidi & $1 x$ & $196 \mathrm{mil}$ & $\begin{array}{l}\text { Quantidade de } \\
\text { seguidores }<200 \text { mil }\end{array}$ & $x$ \\
\hline Kadu Parga & $1 x$ & $83 \mathrm{mil}$ & $\begin{array}{l}\text { Ex-participante de } \\
\text { reality show } \\
\text { Quantidade de } \\
\text { seguidores < } 200 \text { mil }\end{array}$ & $x$ \\
\hline Penélope Nova & $3 x$ & $137 \mathrm{mil}$ & $\begin{array}{l}\text { Ex-apresentadora da } \\
\text { MTV e estudante de } \\
\text { educação física }\end{array}$ & $x$ \\
\hline Michelle Franzoni & $2 x$ & $125 \mathrm{mil}$ & $\begin{array}{l}\text { Quantidade de } \\
\text { seguidores }<200 \text { mil }\end{array}$ & $x$ \\
\hline Vanessa Musskopf & $1 x$ & $45 \mathrm{mil}$ & $\begin{array}{l}\text { Quantidade de } \\
\text { seguidores }<200 \text { mil }\end{array}$ & $x$ \\
\hline
\end{tabular}


(Conclusão)

\begin{tabular}{|c|c|c|c|c|}
\hline Nome do perfil & $\begin{array}{l}\text { Quantidade } \\
\text { de citações }\end{array}$ & $\begin{array}{l}\text { Quantidade de } \\
\text { seguidores }(26 / 07)\end{array}$ & Critério de exclusão & $\begin{array}{l}\text { Atende } \\
\text { aos } \\
\text { critérios }\end{array}$ \\
\hline Thais Conte & $1 x$ & $24 \mathrm{mil}$ & Nutricionista & $x$ \\
\hline Pati Sens & $2 x$ & $220 \mathrm{mil}$ & Nutricionista & $x$ \\
\hline $\begin{array}{l}\text { Isnathan (Nathan } \\
\text { McCallum) }\end{array}$ & $1 \mathrm{x}$ & 320 mil & Não é brasileiro & $x$ \\
\hline $\begin{array}{l}\text { Dieta sem sofrer - } \\
\text { Bárbara }\end{array}$ & $1 x$ & $52 \mathrm{mil}$ & Nutricionista & $x$ \\
\hline Lala Noleto & $1 \mathrm{x}$ & 1 milhão & $\begin{array}{l}\text { Não postou imagem } \\
\text { realizando exercício na } \\
\text { pré-analise }\end{array}$ & $x$ \\
\hline DentistasFit & $1 x$ & $583 \mathrm{mil}$ & $\begin{array}{l}\text { Conta compartilhada - } \\
\text { Fabiano e Alana }\end{array}$ & $x$ \\
\hline Fabulous Fit - Vivian & $2 x$ & $120 \mathrm{mil}$ & $\begin{array}{l}\text { Quantidade de } \\
\text { seguidores }<200 \text { mil }\end{array}$ & $x$ \\
\hline Marina Íris & $3 x$ & $123 \mathrm{mil}$ & $\begin{array}{l}\text { Quantidade de } \\
\text { seguidores }<200 \text { mil }\end{array}$ & $x$ \\
\hline Marcos Mion & $1 x$ & 7,3 milhões & Apresentador de TV & $x$ \\
\hline Guto Galamba & $1 x$ & $246 \mathrm{mil}$ & Prof. de educação Física & $x$ \\
\hline $\begin{array}{l}\text { Frango com Batata } \\
\text { Doce - Rodrigo e } \\
\text { Roberta }\end{array}$ & $4 x$ & 370 mil & $\begin{array}{l}\text { Casal que compartilha } \\
\text { a conta }\end{array}$ & $x$ \\
\hline Jonas Sulzbach & $1 x$ & 1,2 milhões & $\begin{array}{l}\text { Ex-participante de } \\
\text { reality show }\end{array}$ & $x$ \\
\hline $\begin{array}{l}\text { Erasmo Viana } \\
\text { Mahamudra }\end{array}$ & $1 x$ & $802 \mathrm{mil}$ & - & sim \\
\hline Bruno Maffei & & $431 \mathrm{mil}$ & - & $\operatorname{sim}$ \\
\hline Felipe Franco & $1 x$ & 396 mil & $\begin{array}{l}\text { Formado em educação } \\
\text { física }\end{array}$ & $x$ \\
\hline Rodrigo Lima & $1 x$ & 326 mil & - & $\operatorname{sim}$ \\
\hline Fe Camargo & $1 x$ & 402 mil & - & $\operatorname{sim}$ \\
\hline Lucas Gil & $1 x$ & $323 \mathrm{mil}$ & - & $\operatorname{sim}$ \\
\hline Ricardo Barbato & $1 x$ & $224 \mathrm{mil}$ & - & $\operatorname{sim}$ \\
\hline
\end{tabular}

Fonte: Os autores (2016).

Foram excluídos nomes de blogueiros estrangeiros (2). Foram identificados na descrição e excluídas também as listas que indicavam claramente que eram profissionais formados nas áreas de educação física ou nutrição e que tinham contas online (6).

Dos 28 restantes, para a seleção de um grupo heterogêneo de dez blogueiros e observando que as mulheres têm mais seguidores nas contas, achamos necessário excluir algumas usuárias para a inclusão de quatro usuários do sexo masculino e, desse modo, ter uma visão mais geral das postagens. Por fim, os blogueiros que atenderam aos critérios de inclusão e tiveram suas postagens acompanhadas ao longo dos quinze dias ininterruptos (de 14 a 31 de agosto de 2016) foram: Juliana Salimeni, Gabriela Pugliesi, Camila 
Guper, Kéfera Buchman, Carol Buffara, Carol Magalhães, Erasmo Viana, Bruno Maffei, Lucas Gil e Ricardo Barbato, compondo seis mulheres e quatro homens.

A análise das imagens adotou observações quanto aos seus requisitos formais (enquadramentos e composição, cores, filtros) e de conteúdo (cenário, temas abordados, atividades sendo realizadas) ${ }^{12}$. As fotografias foram encaradas como dados passíveis de intepretação, são intenções e registros de uma realidade por parte dos emissores, que organizam os elementos com a intenção de comunicar algo ${ }^{13}$. Assim, também se configuram como discursos. Foram feitas observações das publicações como um todo, ou seja, foram analisadas imagens, legendas (descrição da imagem) e tagueamento (na imagem) e hashtags (na descrição). A análise panorâmica das postagens, a observação dos dados coletados e classificação em tabelas e gráficos permitiram classificar as postagens em categorias temáticas.

\section{Resultados}

Dez perfis no período analisado publicaram 474 imagens. As blogueiras fizeram mais postagens que os blogueiros (333 e 141 respectivamente). A média de postagens dos blogueiros é de cerca de 2,6 postagens/ dia, o que classifica esses usuários como ativos se compararmos com a média de postagens de um usuário comum que é de uma foto a cada 6,5 dias $^{14}$ (JujuSalimeni (maior) com média de 5,11/dia e Lucas Gil (menor) de 1,66/dia). Verificamos inicialmente a quantidade de seguidores de cada um dos blogueiros e classificamos em ordem de 'popularidade'. A Tabela 1 mostra o nome dos blogueiros, a quantidade de seguidores no dia 31 de agosto de 2016 (do maior para o menor), e de posts durante os quinze dias de coleta, e a média de postagens. O ranking tem relação direta com a quantidade de posts dos usuários, sendo o primeiro colocado o usuário que postou mais conteúdo no período analisado.

Tabela 1_Número de seguidores e de posts, média de postagens e ranking

\begin{tabular}{lcccc}
\hline Nome & $\begin{array}{c}\text { Quantidade de } \\
\text { seguidores }^{1}\end{array}$ & Posts $^{2}$ & Média & Ranking $^{3}$ \\
\hline Juliana Salimeni & 9,5 milhões & 91 & 5,11 & 1 \\
Gabriela Pugliesi & 2,6 milhões & 71 & 3,94 & 2 \\
Camila Guper & 757 mil & 35 & 1,94 & 7 \\
Kéfera Buchman & 756 mil & 47 & 2,61 & 4 \\
Carol Buffara & 511 mil & 54 & 3,00 & 3 \\
Carol Magalhães & 400 mil & 35 & 1,94 & 7 \\
Erasmo Viana & 802 mil & 39 & 2,16 & 6 \\
Bruno Maffei & 431 mil & 32 & 1,77 & 8 \\
Lucas Gil & 323 mil & 30 & 1,66 & 9 \\
Ricardo Barbato & 224 mil & 40 & 2,22 & 5 \\
\hline
\end{tabular}

Fonte: Os autores (2016).

Legenda:

${ }^{1}$ Dados de 02 de setembro de 2016;

${ }^{2}$ Postagens de 14 a 31 de agosto de 2016;

${ }^{3}$ Com base na média de postagens.

A maioria das postagens era composta por fotografias (346 ou 73,3\%), sendo 22,4\% destas de vídeos e $4,2 \%$ de textos (imagens que eram compostas por fundos de cores e frases). Juliana Salimeni e Gabriela 
Pugliesi foram as que mais postaram fotografias nesse período, 66/91 e 48/71, respectivamente. A blogueira fitness que postou mais vídeos foi Kéfera Buchman 9/47.

Uma característica apontada da rede social Instagram é a do seu uso para documentar e divulgar viagens e passeios dos usuários. Levando em consideração o ambiente no qual a fotografia foi realizada, e do total de 246 fotografias em ambientes dos dez blogueiros encontramos a seguinte composição: a) fotografia no ambiente doméstico e interno (22\%); b) ambiente de academia/fitness (10\%); c) paisagens de viagens (quando menciona a viagem) (17\%); d) ambientes externos (ruas, calçadas, parques) (35\%); estúdios fotográficos (espaço arquitetônico com controle de iluminação, cenário artificial e equipamentos fotográficos instalados) (16\%).

Durante a fase de coletas observamos que o ambiente doméstico (de sua casa ou de outra residência) foi o segundo local mais referenciado, antecedido por imagens em ambientes externos. Foram 54/246 de imagens em ambientes domésticos, 87/246 em ambientes externos (ruas, praças, praias) e 24/246 em academias. Um aspecto geral classificado refere-se ao conteúdo da imagem; levando em consideração nessa classificação o que está sendo mostrado e destacado na imagem, identificamos em todas elas pelo menos a presença dos seguintes elementos: merchandising de produtos (117); vídeos diversos (106); viagens e lugares (paisagens) (64); imagens estáticas do corpo de blogueiros (38); outros indivíduos e pessoas (26); comidas (refeições, frutas etc.) (26); exercício e treinos (19); textos e frases (18); animais (pets) (15); imagens da mídia (entrevistas ou fotos de televisão ou de jornais) (14); objetos (3).

Destacando a presença do blogueiro na postagem, empreendemos a seleção daquelas em que apareciam efetivamente o corpo do usuário dono da conta. Assim subclassificamos em: 'Selfie': enquadramento quando o usuáriovoltaacâmeraparasi,geralmenteestendendoosbraçosoucomusodedispositivosquedistanciamacâmera, conhecidos como pau de selfies. 'Selfie no espelho': imagens quando o usuário ao invés de voltar a câmera para si, usa o espelho para assim fotografar seu reflexo nele. ‘Corpo inteiro’: quando o usuário por meio de outro indivíduo ou usando recurso de autofotografia com tempo programado na câmera, tira foto mostrando seu corpo por inteiro. 'Partes do corpo': mãos, abdômen, joelhos etc. 'Composer': imagens quando o usuário, usando de programas de edição, seleciona diversas imagens e compõe apenas uma, com diferentes enquadramentos e momentos. A Tabela 2 mostra as postagens de acordo com essa subclassificação.

Tabela 2 - Presença do corpo do blogueiro

\begin{tabular}{lcccccc}
\hline Nome & Selfie & $\begin{array}{c}\text { Selfie no } \\
\text { espelho }\end{array}$ & $\begin{array}{c}\text { Corpo } \\
\text { inteiro }\end{array}$ & $\begin{array}{c}\text { Partes do } \\
\text { corpo }\end{array}$ & Composer & Total \\
\hline Juliana Salimeni & - & - & 09 & 40 & 04 & 53 \\
Gabriela Pugliesi & 04 & 04 & 12 & 19 & - & 38 \\
Camila Guper & 04 & 04 & 09 & 04 & - & 21 \\
Kéfera Buchman & 02 & 03 & - & 01 & - & 05 \\
Carol Buffara & 02 & 01 & 10 & 07 & - & 20 \\
Carol Magalhães & - & 02 & 04 & 12 & - & 18 \\
Erasmo Viana & 04 & - & 04 & 13 & - & 21 \\
Bruno Maffei & 02 & 01 & 05 & 16 & - & 24 \\
Lucas Gil & 06 & 01 & 05 & 05 & - & 17 \\
Ricardo Barbato & 02 & 02 & 12 & 13 & - & 29 \\
\hline
\end{tabular}

Fonte: Os autores (2016).

A identificação e surpresa diante da quantidade de merchandising nos lançaram para a comparação por usuário da quantidade de postagens versus posts com merchandising, conforme destaca a Gráfico 1. 


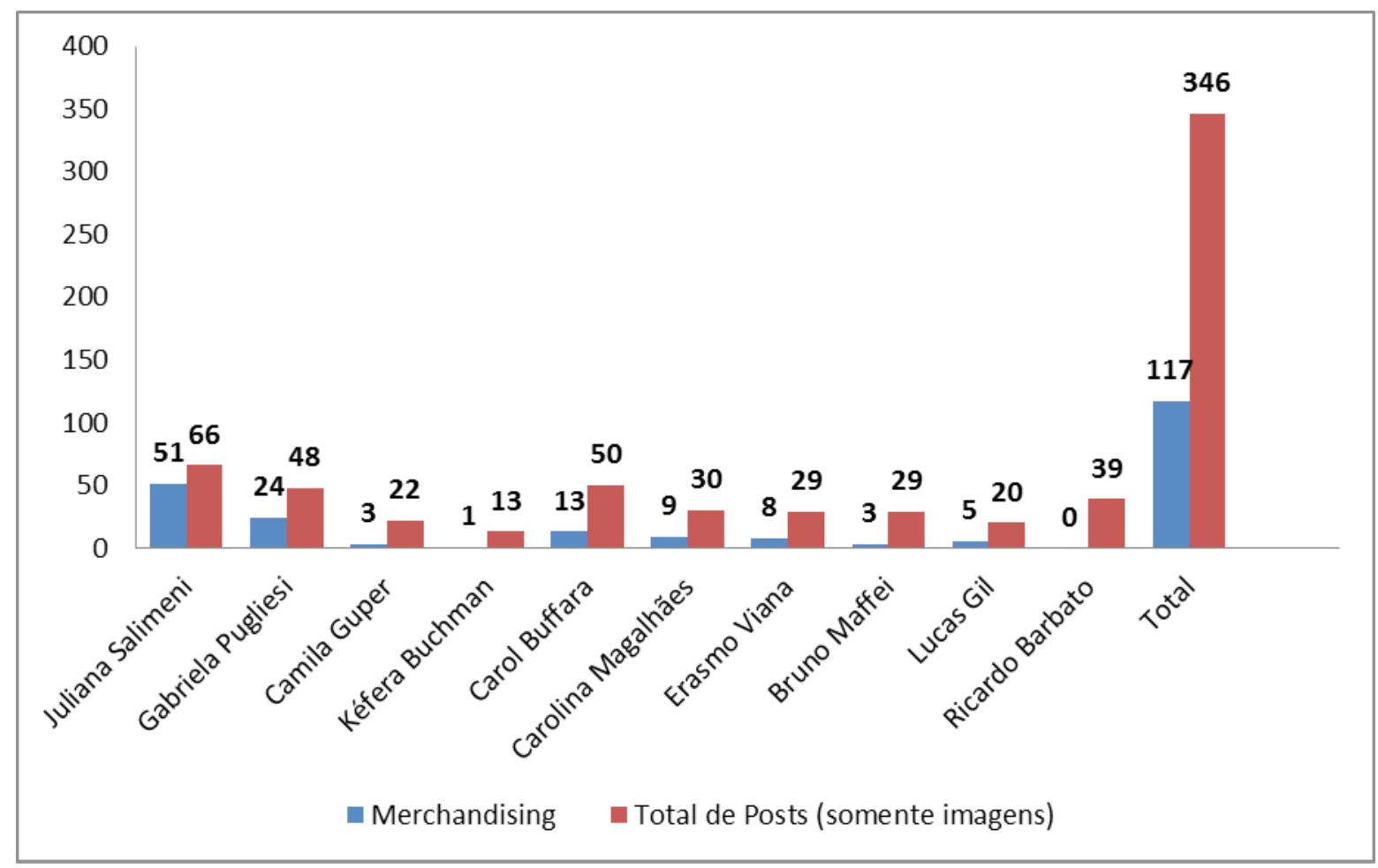

Fonte: Os autores (2016).

Através do Gráfico 1, é possível perceber a alta quantidade de publicações por fotografias de merchandising das blogueiras Juliana Salimeni e Gabriela Pugliesi, 51/66 e 24/48 respectivamente. Quanto ao serviço ou produto que era mencionado/divulgado a Tabela 2 mostra que do total de 346 postagens, 117 foram dedicadas a algum tipo de merchandising e a Tabela 3 categoriza essas postagens de acordo com o produto mencionado. 
Tabela 3 - Produtos e serviços em merchandising editorial nas postagens dos blogueiros fitness

\begin{tabular}{|c|c|c|c|c|c|c|c|c|c|c|c|}
\hline \multicolumn{12}{|c|}{ Quantidade e tipo de merchandising por usuário } \\
\hline Nome & Apps & Roupas*1 & Suplementos*2 & Profissionais*3 & Restaurantes & $\begin{array}{l}\text { Cosmética } \\
\text { beleza }\end{array}$ & $\begin{array}{l}\text { Programa da } \\
\text { mídia*4 }\end{array}$ & Famosos & Fotógrafos & Joias & Petshop \\
\hline G P & 03 & 07 & 04 & 06 & 06 & 02 & - & 02 & 03 & 22 & 11 \\
\hline CG & - & - & 03 & 01 & - & - & - & - & - & - & - \\
\hline K B & - & - & - & 01 & - & - & - & - & - & - & - \\
\hline CM & - & 06 & 01 & 02 & - & 01 & 01 & 01 & 11 & - & - \\
\hline E V & 01 & - & 02 & 07 & 05 & - & 01 & 02 & 2 & - & - \\
\hline B M & 01 & 02 & 01 & 07 & - & 01 & - & - & - & - & - \\
\hline L G & - & 04 & 01 & 06 & - & - & - & - & - & - & - \\
\hline R B & - & - & - & - & 01 & - & - & - & - & - & - \\
\hline
\end{tabular}

Fonte: Os autores (2016).

Legenda:

${ }^{*}$ Produtos para treino (luvas, tênis, bags);

${ }^{*}$ Alimentares (bebidas energéticas e comidas);

*3 Médicos, personal trainers, dentistas, farmacêuticos, clínicas de estética;

*4 Menções a programas na TV, participação em programas de rádio ou outro veículo de comunicação.

A tabulação levou em consideração a classificação de Schiavo, adaptando-a do contexto audiovisual para o cenário online. Assim, adotou-se a seguinte classificação: a) Explícito - quando o produto aparece claramente na imagem da postagem; b) Presente apenas comentários; ec) De forma combinada - na imagem e nos comentários. Dentre os produtos que mais mereceram destaque e que serão comentados nesse artigo estão os suplementos alimentares (ver Tabela 2). Joias e petshops não tiveram distribuição para todos os usuários, e embora roupas esteja em segundo lugar na quantidade geral de postagens, sua categoria merecerá um futuro olhar. 


\section{Discussão}

Um aspecto bastante relevante observado nos dados foi a presença constante de merchandising e divulgação de produtos, serviços e profissionais (ver Gráfico $1 \mathrm{e}$ Tabela 2). Acompanhando dez perfis fitness do Instagram, observou-se que o merchandising é uma constante. Como a terminologia 'merchandising' é bastante ampla e é usada diferentemente pelos profissionais da comunicação, resolvemos adotar o termo "merchandising editorial" proposto por Schiavo ${ }^{15}$ no contexto do produto audiovisual para fazer referência à estratégia promocional aplicada ao material, e pode ser classificado em: 1) Com menção no texto: quando os personagens de um filme referem o nome da marca; 2) Quando os personagens usam o produto na cena (ex: beber, manipulam o smartphone...); 3) Conceitual: quando o personagem explicita para outros as vantagens, inovações e preços do produto e; 4) Estímulo visual: o produto é mostrado de forma a ser apreciado, visto no contexto da cena e explorado pela câmera. Suplementos alimentares aliados a fotos dos corpos e com alimentos 'saudáveis' se destacaram como categoria de produto bastante divulgado pelos blogueiros.

\section{Corpos (selfies e narcisismo)}

Nesta categoria, agrupamos as imagens em que o corpo do blogueiro está em destaque e analisamos a forma como os suplementos alimentares são citados ou aparecem nas postagens. Foram postadas 246 imagens com a presença do corpo em cada uma (246/472) destacado em primeiro plano (JujuSalimeni 53/Kéfera Buchman cinco). A selfie apareceu em dezoito postagens do sexo masculino (18/141) e em 26 do feminino (26/333).

Rettberg ${ }^{16}$ nos lembra como essa exposição da imagem de si, presente nas redes sociais como o Instagram nos dá elementos para pensarmos que temos uma intimidade com o usuário. $O$ próprio ato fotográfico confirma em si uma intencionalidade do indivíduo que tira a foto e que é retratado, e, no caso, seu compartilhamento público numa rede como o Instagram, a vontade de ser notado e visto. Embora muito já tenha se discutido sobre a fotografia como um espelho, recorte, representação e uma realidade ${ }^{17,18}$, nas postagens há intenção publicitária de vender os produtos/serviços a elas associados. Se considerarmos que o Instagram é comumente visto como um app que melhora a qualidade da imagem, 'maqueando-a' por meio de filtros e edições, podemos interpretar essas imagens como próximas ao conceito de hiper-real trabalhado por Baudrillard ${ }^{19}$.

Numa visão mais psicológica desse ato, as imagens do Instagram, dos corpos em situações de prazer e o hedonismo associado às imagens trazem, como consequência, uma desvalorização do passado e a procura do prazer intenso, impulsivo e momentâneo, em busca de gratificações imediatas ${ }^{20}$. Dessa forma, alguns pensadores mais pessimistas da cultura contemporânea apontam para o crescimento da banalização das relações pessoais, com pouca condição de se transformarem em vínculos mais duradouros ${ }^{21}$.

A crise mais ampla da modernidade incidiria então na construção da subjetividade contemporânea, ou seja, na própria constituição do sujeito psíquico. Dois aspectos se destacam nesse sentido: a menção do gradual aumento de características narcisistas de personalidade ${ }^{22,23}$, na qual vemos as postagens dos corpos como um ícone dessa qualidade, e também de estados afetivos depressivos identificados em estudos internacionais ao longo das últimas décadas ${ }^{24}$.

Com relação ao narcisismo e à ligação entre sujeito e corpo na contemporaneidade, Lasch $^{25}$ menciona que este se refere a uma preocupação exacerbada com as formas de realização individual privada, em que os projetos individuais pululam e se destacam nas sociedades de massa do capitalismo. A palavra 'narcisismo' origina-se justamente do mito de Narciso, jovem grego que se apaixona por seu reflexo na água e se afoga, e é utilizada na psicologia para descrever pessoas autocentradas, com grande apreço a si próprias. Podem exibir egoísmo, sentimento de superioridade e excessivade de autoadmiração. Essa 
forma egoísta de comportamento pode danificar a habilidade para manter e se beneficiar de relações saudáveis com outras pessoas ${ }^{26}$.

Pelo outro lado da tela, na perspectiva do público, o fenômeno do narcisismo se mostra um misto de idolatria e vontade de aparecer. Os autorretratos, ou as selfies, como são chamados atualmente, podem ser especialmente instrutivos, pois estão em boa parte da literatura associadas à "cultura do narcisismo" ${ }^{27}$. Outros pesquisadores, no entanto, preferem identificar as pessoas que tiram selfies como indivíduos mais "autoconfiantes"

Pelo Instagram ser um app de smartphone, o que facilita fazer e compartilhar selfies, tínhamos expectativa de encontrar uma grande quantidade desse tipo de composição nas postagens dos blogueiros, algo que não se verificou após coleta dos dados. JujuSalimeni, por exemplo, foi a blogueira que mais postou no Instagram durante o período analisado (53/246), sendo 246 o total de posts da usuária, mas não apresentou nenhuma selfie (tradicional ou no espelho) durante o período de coleta. Os usuários que mais postaram selfies foram Camila Guper (08/35) e Gabriela Pugliesi (08/71) ainda que esses números representem uma quantidade baixa diante da literatura que destaca o selfie como o enquadramento do momento ${ }^{16}$. A nossa percepção é que o selfie ainda remete a uma produção mais amadora, visto que a qualidade de resolução das imagens e de produção (com o recurso de maquiagem) mostram que as fotografias são elaboradas e/ou pouco espontâneas. Nossos dados mostram que a blogueira JujuSalimeni tirou 22 fotos em estúdios fotográficos, do total de $53 \mathrm{em}$ que aparece o seu corpo (22/53), o que indica o acesso a profissionais da fotografia e, por isso, dispensou fotografias amadoras, com as quais o selfie pode ainda estar associado.

Mesmo que as fotos sejam trabalhadas com iluminação, os participantes dessa rede evitaram compartilhar imagens modestas de si e, quando no ambiente doméstico, a foto era pensada e posada, como se fosse um patamar simbólico de distinção, ou seja, os usuários postaram fotos em "embalagens perfeitas e bem feitas de si” - o que é uma característica geral dessa presentificação do eu ${ }^{29}$ nas redes sociais online, em especial no Instagram ${ }^{30,31}$. O uso de filtros que melhoram a textura, iluminação e contraste nas imagens foi verificado em todas as contas seguidas, ou seja, com alta frequência as imagens foram melhoradas; embora aparentem naturais, denotam uma preparação seja no pré, na pose e na pós-produção da imagem (edição e filtros). Esse exercício de produzir imagens mais profissionais e menos amadoras sugere que os blogueiros querem aumentar sua visibilidade e garantir o retorno esperado pelo investimento em marketing - que valoriza a qualidade do conteúdo.

Não podemos desconsiderar que a exposição do corpo vinha acompanhada de textos que valorizavam a luta, manutenção e conquista do corpo perfeito. Embora não estejam voltando a câmera para si, como na selfie, o discurso e o conteúdo se ligam efetivamente ao usuário proprietário, o que é inclusive uma característica geral da própria rede. Um estudo adicional investigou a relação entre a frequência de uso das redes sociais, com empatia e narcisismo e identificou que homens e mulheres que postam, comentam e tagueiam fotos com mais frequência estão associados a índices maiores de narcisismo ${ }^{26}$. As contas apresentaram muitas imagens em que os blogueiros aparecem nos mais diversos enquadramentos (246 de 472). O plano geral e o plano americano (79/246) empatam na quantidade total de postagens em que o corpo está destacado, sendo o plano médio (32/246) o segundo colocado. Desses, vale destacar a preferência da blogueira JujuSalimeni pelo uso do plano americano (32/53) (enquadramento que destaca uma ação e permite visualizar o corpo dos joelhos para cima).

Esse universo da autoimagem nas RSO, desse narcisismo e exposição do $e^{27}$ pode remeter ao padrão de beleza divulgado pela mídia ${ }^{32,33}$ e historicamente construído. Compreendemos, assim, porque grupos de feministas e ativistas usam justamente o Instagram para criticar essa exibição e objetificação do corpo tido como correto, belo e ideal ${ }^{34,35}$. Essa busca do corpo ideal alcança majoritariamente as mulheres, que são inclusive as mais acometidas por transtornos alimentares ligados à autoimagem ${ }^{36,37}$. Ao mesmo tempo, não se pode desconsiderar que esses blogueiros podem servir como referência positiva para incentivar 
pessoas a fazer atividades físicas e manter alimentação saudável, algo que parece transparecer em alguns comentários de seguidores.

Apesar da literatura sobre corpo fitness focar no corpo feminino ${ }^{38,39}$, também foi verificada nesta pesquisa exibição dos corpos dos usuários masculinos. Descamisados, os usuários do sexo masculino reforçam o abdômen. No exemplo do post1 de Ricardo Barbato, em 29 de agosto, vimos que o usuário levanta a sua camisa em uma selfie pelo espelho chamando a atenção para a forma do seu abdômen. Enquadramentos semelhantes estão em Bruno Maffei_post1 dia 14 de agosto, Erasmo Viana_post1 dia 23 de agosto e LucasGil_post1 dia 22 de agosto. As postagens que valorizam o corpo e destacam coxas e glúteos foram de 101/333 para mulheres. Percebeu-se que os blogueiros costumam comentar sobre as conquistas e demonstrar o esforço (das atividades e exercícios físicos) para se ter aquele corpo. Essa característica de mostrar apenas parte do corpo ficou bastante perceptível na usuária JujuSalimeni, com o total de 40 postagens de 53 em que se destaca alguma parte de seu corpo, em especial as pernas (coxas). Essas imagens reforçam o que Novaes ${ }^{40}$ menciona sobre o corpo, no registro imaginário, ou seja, uma possível demarcação do dentro e fora, e se torna o local de signos culturais, que incluem, sobretudo, a aparência: postura, vestimentas, práticas corporais etc. Para ela, “[...] o corpo é então compreendido como uma exteriorização do interior psíquico do sujeito, fazendo, dessa maneira, a fronteira entre o individual e o social”. A blogueira Kéfera foi a que menos postou imagens de detalhes de algum membro de seu corpo (1/5), sendo cinco o número de imagens em que há uma valorização do seu corpo na foto.

\section{Alimentos e suplementos}

Ao se observar o comportamento de consumidores em mídias sociais como o Instagram, caracterizado pela exposição de imagens e fotos, é possível identificar que algumas aparições do corpo estão associadas ao alimento consumido. Foram seis postagens de três usuários (Camila Guper/Kefera/Ricardo) que associaram o corpo com a comida e 26 postagens de seis usuários que postaram imagens com destaque único para o alimento.

Essas imagens e a qualidade do alimento presente lembram que, para Canesqui e Garcia ${ }^{41}$, no atual padrão de beleza, é necessário não ceder às tentações dos alimentos. O alimento se apresenta como elemento essencial para se conquistar ou manter o corpo fitness. Assim, vimos também que essa exposição do corpo esteve associada à presença de suplementos alimentares. Em um dos posts, no dia 25 de agosto, por exemplo, a blogueira Camila Guper faz menção ao suplemento que utiliza nos comentários da postagem e tem o merchandising do produto explícito na fotografia. Camila está encostada no lado externo de uma porta, com a barriga à mostra, olhando para baixo e sorrindo. Em seu pescoço estão fones de ouvido e roupas e tênis de atividade física, em um de seus braços vemos a embalagem de suplemento. Na descrição, ela destaca o produto e sinaliza que se trata de uma imagem do pós-treino:

"Já fui (emojis) Pós-treino de sempre @metapure_qnt sabor chocolate belga (emojis) sempre levo comigo duas doses de proteína, assim não preciso comer besteira na rua! Hoje o dia vai ser agitado (emoji) \#workout \#Love \#mylifestyle”.

Já na Figura 2, post2 dia 18 de agosto, vemos Camila Guper segurando o pote de suplemento alimentar com a presença de seu animal de estimação ao lado. 




Figura 1 - Camila Guper: Post2 do dia 18 de agosto de 2016 Fonte: Instagram (2016).

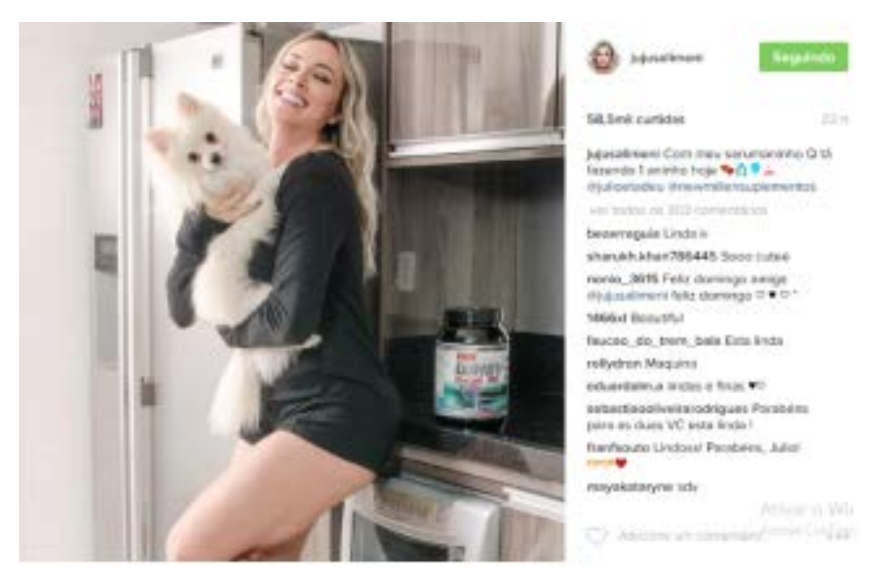

Figura 2 - Juliana Salimeni: Post3 do dia 20 de agosto de 2016 Fonte: Instagram (2016).

Apesar de não estar diretamente nas mãos dos blogueiros, a Figura 2 (post3 dia 20 de agosto) mostra um recurso utilizado por alguns desses usuários. Na imagem, em um ambiente doméstico com seu animal de estimação no colo, vemos ao seu lado a embalagem de suplemento alimentar. Ambos foram tagueados pela blogueira na descrição da imagem, conforme a descrição:

“Commeu serumaninhoQtáfazendo1 aninhohoje,(emojis)@juliotadeu@newmilleniumsuplementos”.

No post2 do dia 22 de agosto, a blogueira Gabriela Pugliese beija a embalagem de um produto, sentada em um sofá, destacando na descrição o sabor de café do produto, que tem a descrição de seu personal trainer e onde se encontra o produto.

O aspecto naturalizado da inserção do produto na imagem é o que lemos também na postagem 9 do dia 15 de agosto de Juliana Salimeni; na descrição, ela destaca o produto:

"Hoje foi o treino de dorsais, abs e 30 min de escada @madrugadaosuplementos".

Já o post do dia 8 de agosto reforça o merchandising do produto, ao trabalhar a imagem editada com a inserção de banners gráficos indicando descontos no site do produto. Em outra postagem (a 4), no dia 20 de agosto, vemos Juliana Salimeni, indicando a marca do suplemento que ela consome; na imagem, ela 
esboça um sorriso com dedo na boca, segurando duas embalagens do produto, com cabelo e iluminação trabalhados. No post1, dia 23 de agosto, Erasmo Viana, sem camisa, no interior de uma residência, e em plano médio com a cabeça levemente abaixada, prepara o suplemento e descreve:

"Tanto na musculação quanto nos treinos ao ar livre, eu exijo muito do meu corpo. Eu uso A-Bomb da MHP, pois diminui minhas dores musculares e ainda tem citrulina, que dá aquele gás durante meu treino. \#FAstNutri \#PreTreino \#MHPBrasil \#EuSouFastNutri”.

É dele um post bastante curioso, post1 dia 30 de agosto, ele realiza exercício de levantamento numa barra e encaixada no meio das suas pernas está a embalagem do suplemento com o rótulo voltado para a câmera; na descrição há um reforço e detalhes sobre o produto:

"Todo mundo sabe a importância de uma boa suplementação para aqueles que buscar melhorar sua performance. Sou consumidor de proteína há muito tempo e sempre uso nos meus shakes ou receitas de comida. O Carnivor da MuscleMeds é excelente para minha dieta, pois é livre de gordura, lactose, colesterol e glúten. Você encontra na FastNutri.com.br (emoji punho fechado) \#FastNutri \#Carnivor \#MuscleMeds \#EuSOuFastNutri”

O post2, dia 31 de agosto, de Carol Buffara é um exemplo da associação entre imagens de alimentos saudáveis, como frutas e sucos, com a presença do suplemento. Nessa imagem, tirada de cima, vemos em parte um prato colorido cheio de morangos, uma jarra de suco verde, e abaixo um prato com uvas. Sobre a mesa e com os rótulos voltados para a câmera estão duas embalagens do produto que a descrição da foto destaca:

"Além de tentar me alimentar da forma mais saudável e balanceada possível, gosto de alguns suplementos e vitaminas para complementar minhas necessidades nutricionais! Todos os dias, no café da manhã tomo as vitaminas @sundown_vitaminas! Elas não engordam, são sem glúten, sem lactose e sem sabor artificial!”.

O post continua descrevendo as qualidades do produto e finaliza com as seguintes hashtags:

“\#paravocêvivermais \#VitaminasSundown @sundown_Vitaminas \#publi”

Embora os suplementos alimentares sejam largamente utilizados e considerados seguros, alguns deles despertam reações adversas e, em alguns casos, seu uso indiscriminado pode levar à morte ${ }^{42}$. Nos Estados Unidos, o órgão Food and Drug Administration (FDA) é o responsável por monitorar os suplementos e garantir que sejam seguros. No entanto, os protocolos não são sempre efetivos, o que justifica o interesse de pesquisadores em buscarem comentários de reações adversas nas redes sociais online para assim identificar relatos e casos de usuários compartilhando más experiências com os produtos ${ }^{42}$. No Brasil, o controle é feito pela Agência Nacional de Vigilância Sanitária (Anvisa), que em junho de 2017 lançou o Suplementos alimentares: Documento de base para discussão regulatória ${ }^{43}$, apresentando um resumo dos principais marcos da proposta de regulamentação dos suplementos alimentares, que é subtema da Agenda Regulatória. No texto, lemos: "Atualmente, não existe na legislação sanitária uma regulamentação específica para essa categoria, sendo que os fabricantes e os importadores necessitam considerar uma diversidade de normas de alimentos e de medicamentos para sua regularização no país"43.

Esses suplementos alimentares incluem uma categoria vasta de produtos, mas falamos aqui de alguns vendidos para perda de peso e ganho muscular ${ }^{44}$. São produtos que incluem laxantes e diuréticos, bastante 
vendidos online, em lojas de saúde/fitness ou farmácias e têm boa aceitação pelo consumidor porque geralmente oferecem resultados rápidos, saudáveis e fáceis. No entanto, pesquisas experimentais apontam para problemas de saúde, inclusive em populações mais vulneráveis ${ }^{45}$, como jovens e adolescentes ${ }^{46}$. Sérias consequências para a saúde associados ao consumo sem acompanhamento desses suplementos, bem como o aumento do risco de adquirir doenças são listados pela literatura cientifica: infarto do miocárdio, câncer de testículo, problemas gastrointestinais, danos aos órgãos como rins, fígado e ossos, e podem levar a morte ${ }^{47,48}$. A presença desses produtos no merchandising levanta a questão relativa à exposição de usuários frente a essas marcas e produtos, uma vez que identificamos nesses blogueiros um poder de influenciar parte de sua 'audiência' de seguidores. A proposta do merchandising nas fotos ocorreu predominantemente de forma combinada (com a imagem do produto e descrição 'comentário' sobre a foto). Essa tendência natural de incorporação de publicidade em contas mais seguidas é observada de forma geral nas RSO, já que percebemos uma mudança na forma de divulgar produtos, que antes era feita claramente por meio da publicidade e, hoje, está diluída e menos formal ${ }^{49}$. Isso se deve também ao perfil do usuário de redes sociais estar menos disposto a consumir publicidade direta, mesmo quando ele desconhece que seu comportamento e interação online são convertidos em dados para direcionar a publicidade de forma mais "customizada" ${ }^{\circ}$. A partir de alguns comentários, observou-se que os seguidores consomem a publicidade velada, já que demonstram interesse pelos produtos e ainda dialogam dentro das RSO com amigos sobre os mesmos, tagueando-os, o que pode ampliar o impacto do produto divulgado. Cabe lembrar que seguir e interagir com os perfis fitness permite às redes reconhecerem interesse e criarem um perfil de consumo do usuário. Considerando inclusive que o Instagram é um sistema da empresa Facebook Inc., o cruzamento do comportamento online nessa plataforma com outras (Facebook, WhatsApp) permite as empresas de marketing uma compreensão maior dos interesses do usuário e, assim, direcionar publicidade com maior taxa de conversão em compra pelo usuário.

A exposição da imagem do corpo e o consumo de suplementos alimentares nos remete ao ambiente das academias. No entanto, apenas 24 fotografias do total de 472 postagens foram tiradas em ambientes por nós reconhecidos como academias profissionais. Pelo pequeno número, fica claro que esses usuários não se limitam a postar imagens realizando exercícios físicos somente nesse ambiente, mas transpõem essas atividades para os ambientes externos, em viagens e no ambiente domiciliar - incluindo em equipamentos instalados no espaço doméstico.

Constatam-se, assim, novas estratégias de marketing e publicidade que incluem usuários com alto índice de popularidade na rede como 'garotos e garotas propaganda', bem como a divulgação e exposição de hábitos de consumo, geralmente por enunciadores que se destacam em seu circuito interacional próprio, ganham seguidores e fãs em números notáveis e se veem como formadores de opinião, influenciando os hábitos de seus seguidores ${ }^{51}$. Confirmando que esse universo é lucrativo para alguns blogueiros, uma reportagem para o site de notícias G1 mostrou uma entrevista com Gabriela Pugliese sobre quanto se cobra por uma publicidade em seu perfil e as parcerias: "Algumas marcas que eu usava começaram a querer patrocinar meu blog (Tips 4 Life). Um tempo depois, consegui largar meu emprego" 52 . Na mesma reportagem, ela indica que está usando a hashtag 'publi' para sinalizar que o post é patrocinado para os seguidores e garantiu que "fazer parcerias com marcas e serviços nos quais ela 'acredita"'52? O site apurou que ela fatura cerca de R $\$ 200$ mil por mês, indicando inclusive que o post pode estar atrelado a um pacote de ações que inclui bônus e viagens pagas.

A imagem corporal desses blogueiros e a associação com o suplemento alimentar promovem a ideia de um corpo tecnologizado, conquistado somente após a mediação do suplemento e da biotecnologia. É nesse novo cenário que podemos pensar juntamente com Saldanha ${ }^{53}$ para quem: "[...] o corpo se transforma em um espetáculo à parte, podendo ser comparado a uma máquina na qual é possível adicionar vários acessórios e até mesmo mudar algumas peças." Para ele, os tratamentos estéticos, as dietas e os suplementos alimentares funcionam 
como acessórios e as cirurgias plásticas "seriam as trocas de peças. Tudo em prol do bem-estar e da preocupação com o físico".

A exposição desses perfis com a presença do discurso tido como 'saudável' acaba reforçando um estilo de vida que se ampara no discurso da 'saúde' para conquistar notoriedade. Consequentemente, o corpo deve ser comedido, comportado e controlado, uma vez que o excesso é visto como um risco ao bem-estar e, dentro dessa perspectiva, o desleixo e/ou a falta de cuidado consigo mesmo traria como resultado a doença. Cabe contextualizar que, no Brasil, há interesse em cirurgias estéticas e de intervenção diretas no corpo a fim de adequá-lo a um 'padrão' tido como aceitável pela sociedade, atraindo mulheres de outros países para sofrerem essa intervenção ${ }^{54}$. De acordo com números divulgados pela Sociedade Internacional de Cirurgia Plástica, mais de 23 milhões de intervenções foram realizadas globalmente no ano de 2013, sobretudo por pacientes mulheres $(87,2 \%)$. Os números evidenciam que o uso das biotecnologias para a modificação dos corpos tem mais impacto sobre as mulheres. A cooptação das tecnociências pelo capitalismo e seu alinhamento com alguns discursos midiáticos acaba por produzir o fenômeno da busca do ‘corpo perfeito', o que certamente é uma das motivações para as intervenções médicas com finalidades meramente estéticas ${ }^{55}$. O corpo apresentado por esses blogueiros parece, então, confirmar as observações de Sauerbronn, Tonini e Lodi ${ }^{5}$, quando analisaram a publicidade de suplementos alimentares em outros veículos (diferentes do Instagram) de que o corpo é confirmador da ação do produto. Para eles, o corpo representado na publicidade desses produtos "não centraliza a expressão de valor, tampouco é mostrado apenas como o local onde o produto age, mas serve como confirmação do produto".

Além das intervenções diretas por cirurgias, os suplementos alimentares também entram como tecnologias para modificação do corpo. Hoje, vive-se exaltando corpos magros, fortes e definidos, tidos como saudáveis e questões como boa alimentação, uma rotina diária de exercícios e a preocupação em se manter determinado equilíbrio entre o físico e a mente são entendidas como elementos que dão qualidade à vida das pessoas ${ }^{53}$. A tecnologia para ampliar a capacidade do homem aparece nesses discursos quando estes indicam o interesse em substâncias para o pré-treino e também no imaginário construído em torno do poder e eficiência dos suplementos. Em pesquisa com abordagem etnográfica em academias no Rio de Janeiro, Sabino, Luz e Carvalho ${ }^{57}$ lembram que o encantamento produzido por suplementos alimentares está associado também a imagens de corpo musculoso, e à promessa de consumo de uma proteína que é mais apropriada para a absorção do que a 'natural'. Os suplementos industrializados, "tornam-se distantes de sua matéria-prima e se apresentam limpos de tudo o que pode ser considerado ‘pesado' ou ‘sujo'.”. Crítica comum a esse universo também chamado de fitinspirador é que o contato com essas imagens pode contribuir para que o usuário foque muito no exercício em busca da aparência mais do que nos benefícios gerais para a saúde, com o objetivo de adquirir um tipo físico atlético ${ }^{58}$. A interiorização desse tipo atlético ideal tem sido associada com o aumento compulsivo do exercício e uma emoção negativa quando o usuário perde um dia de treino ${ }^{59}$. Por outro lado, considera-se esses formadores de opinião como responsáveis por despertar o interesse de diversos usuários para a prática de atividade física e alimentação mais saudável, como vimos figurar rapidamente em alguns comentários em postagens dessas contas. É nessa dicotomia do ciberespaço que profissionais e promotores da saúde se preparam para novos desafios da saúde coletiva.

\section{Considerações finais}

Ser blogueiro se tornou profissão para alguns jovens que investiram nesse espaço comunicacional e, como consequência, possuem alto rendimento obtido com publicidade e presença em eventos. Além disso, alguns blogueiros alcançaram status de celebridades, rompendo as barreiras do ciberespaço, com a exposição nos veículos de comunicação de massa e representam o tipo de personalidade ou estilo de vida que os seguidores dessas contas gostariam de ter. Como percebemos, as publicações que trabalham com 
o tema ou com a rede social Instagram podem condicionar comportamentos não saudáveis no campo da alimentação/distúrbios alimentares ${ }^{8,39}$ dos usuários expostos a ela, ou pela propagação da imagem ideal de corpo e beleza ${ }^{9,60}$. O universo fitness vem despertando atenção em algumas publicações ${ }^{61}$, bem como a representação de algumas práticas esportivas, como a ioga, por exemplo ${ }^{62}$. No entanto, essas pesquisas apresentaram aspectos mais globais, de perfis e contas estrangeiras. Sobre blogueiros fitness brasileiros, podemos citar o artigo de Batista e Rodrigues ${ }^{61}$ que analisou as postagens de três perfis: Gabriela Pugliesi, Bianca Anchieta e Carol Buffara, mas que não especificam claramente o período de coleta dos dados e interpretaram as postagens à luz da teoria de Goffman e de representação social/identidade.

Nossa pesquisa revelou a forte presença de merchandising e divulgação de produtos nas postagens. Elemento esse que ganhou força nos últimos anos com o aumento da visibilidade da rede Instagram e dos investimentos em comunicação. A presença dos suplementos alimentares nessas postagens e a falta de regulação do tipo de publicidade que pode ser vinculada nas redes sociais, sem sinalização, levanta importantes questões para a saúde coletiva.

Os blogueiros nesta pesquisa são brancos, moram em grandes cidades e, aparentemente, possuem renda financeira boa. Um estudo com usuários mais 'amadores' e com diversidade social, racial, poderia nos indicar novas percepções/formas de criar, endereçar conteúdo e se relacionar com sua audiência. Outra possibilidade aberta é a de automatizar a busca, usando o Application Programming Interface (API) do Instagram e assim construir um novo panorama baseado em contas de outros usuários, com estudos mais automáticos na coleta e análise dos dados. A análise dos metadados, localização das postagens, frequência de visualização e outros aspectos podem indicar padrões imperceptíveis com a metodologia de coleta mais manual que adotamos.

Nossos resultados confirmam que há um ideal de beleza no imaginário feminino e masculino, e a homogeneização dos corpos dos blogueiros selecionados sugere o mesmo perfil: magros e malhados. Esse corpo é presente em outras mídias (TV, revistas etc.) e se reflete nas redes sociais. Uma pesquisa mais profunda sobre a recepção e comentários de postagens de usuários com padrão corporal que foge a essa lógica pode fornecer subsídios para comparações, discriminação, bullying e representação. Desconsideramos para essa pesquisa também, os comentários e interações com os usuários de uma forma mais aprofundada e sistematizada. Aparentemente, a comunidade de seguidores não é tão passiva e muitos deles questionam, em diversos momentos, a qualidade do conteúdo postado.

Se considerarmos que o aplicativo Instagram é apenas uma rede de outras dezenas populares e com seguidores, abrimos oportunidade para estudos comparativos entre redes, com a possibilidade de identificação de nichos e de ações de promoção da saúde multimodais (por foto, vídeo, texto) e multimídia (Instagram, Flickr, Snapchat, Facebook). Outra perspectiva aberta pela nossa pesquisa e que serve como uma sugestão é a do uso do app como ferramenta de comunicação entre profissional da saúde e paciente ou usuário e como ferramenta para divulgação de conteúdo mobilizador.

'Seguir' dez blogueiros fitness ao longo de quinze dias foi apenas a formalização de uma experiência de contato com essas contas que antecede e é posterior a essa fase de coleta de dados. Os dados coletados permitiram dar uma visão geral sobre alguns aspectos do conteúdo dessas contas que merecem atenção de pesquisadores do campo da saúde, e em especial e no nosso caso, promotores da saúde. Foram excluídos os blogueiros que eram atores e atrizes, e os que tinham formação acadêmica na área da saúde (educadores físicos, nutricionistas, esteticistas). Futuras pesquisas poderiam comparar as ações de promoção de saúde de blogueiros sem formação acadêmica versus blogueiros com formação acadêmica, verificando se os últimos têm efetivamente respeitado o conhecimento e os preceitos éticos de sua profissão. A migração de agências e promotores da saúde para as redes sociais online pode funcionar como 'antídoto' da informação equivocada presente nas postagens dos usuários. Assim, no que se refere à presença de discursos saudáveis ou não nas redes sociais online, surge a necessidade de estabelecer diálogos em conjunto entre os diferentes segmentos e profissionais para assumirmos a responsabilidade sobre a qualidade de vida da população. 


\section{Referências}

1. Caputo V. Os 10 apps mais baixados no Brasil em 2015. Exame [Internet]. 2016 set. [citado em 2016 nov. 11]. Disponível em: https://exame.abril.com.br/tecnologia/os-10-apps-mais-baixados-no-brasil-em-2015/

2. Manovich L. Instagram and contemporary image [Internet]. Los Angeles; 2017. Disponível em: http:// manovich.net/index.php/projects/instagram-and-contemporary-image

3. Silva PIR. Dinâmicas comunicacionais na representação da vida cotidiana. Instagram: um modo de narrar sobre si, fotografar ou de olhar para se ver [Internet]. Resumos do INTERCOM: Sociedade Brasileira de Estudos Interdisciplinares da Comunicação; 170 Congresso Brasileiro de Ciência da Comunicação [Internet]; 2012 jun. 28-30; Ouro Preto, MG. São Paulo: INTERCOM; [citado em 2013 jun. 2]. Disponível em: https://goo.gl/Doopiy

4. Moon JH, Lee E, Lee J-A, Choi TR, Sung Y. The role of narcissism in self-promotion on Instagram. Pers Individ Dif [Internet]. 2016 Oct [cited 2017 Feb 2];101:22-5. doi: http://dx.doi.org/10.1016/j. paid.2016.05.042

5. Lee E, Lee J-A, Moon JH, Sung Y. Pictures speak louder than words: motivations for using instagram. Cyberpsychology. Behav Soc Netw [Internet]. 2015 Sept [cited 2016 Feb 2];18(9):552-6. doi: https:// doi.org/10.1089/cyber.2015.0157

6. Tanner E. Girls, Instagram, and the glamorization of self-loathing girls. Dissent Voices [Internet]. 2015 [cited 2016 Feb 2];4(1):105-20. Available from: https://digitalcommons.brockport.edu/cgi/viewcontent. cgi?article $=1046 \&$ context $=$ dissentingvoices

7. Lup K, Trub L, Rosenthal L. Instagram \#instasad?: exploring associations among instagram use, depressive symptoms, negative social comparison, and strangers followed. Cyberpsychol Behav Soc Netw [Internet]. 2015 May [cited 2016 Feb 2];18(5):247-52. doi: https://doi.org/10.1089/ cyber.2014.0560

8. Kosek B. The influence of Instagram on exercise and eating behavior. Honor Proj Mark [Internet]. 2015 Apr [cited 2016 Feb 2]:1-15. Available from: https://goo.gl/KCEUQa

9. Lewallen J. When image isn't everything: the effects of Instagram frames on social comparison. J Soc Media Soc [Internet]. 2016 [cited 2016 Oct 12];5(2):108-33. Available from: https://goo.gl/jp93Q9

10. O risco dos blogs fitness. R Educ Física [Internet]. 2015 jun. [citado em 2017 dez. 30];56:20-1. Disponível em: https://goo.gl/WfNmxj

11. Bardin L. Análise de conteúdo. Lisboa: Edições 70; LDA; 2009.

12. Coutinho I. Leitura e análise da imagem. In: Duarte J, Barros A, organizadores. Métodos e técnicas de pesquisa em comunicação. 2. ed. São Paulo: Atlas; 2006.

13. Banks M. Dados visuais para pesquisa qualitativa. Porto Alegre: Artmed; 2009.

14. Manikonda L, Hu Y, Kambhampati S. Analyzing user activities, demographics, social network structure and user-generated content on Instagram [Internet]. Ithaca: Cornell University Library; 2014 [cited 2016 Oct 12]. Available from: http://arxiv.org/abs/1410.8099

15. Schiavo MR. Merchandising social: uma estratégia de socioeducação para grandes audiências. Rio de Janeiro; Universidade Gama Filho; 1995.

16. Rettberg JW. Seeing ourselves through technology: how we use selfies, blogs and wearable devices to see and shape ourselves [Internet]. London: Palgrave Macmillan UK; 2014 [cited 2016 Oct 12]. Available from: http://link.springer.com/10.1057/9781137476661

17. Barthes R. A câmara clara. Lisboa: Edições 70; 2006.

18. Dubois P. O ato fotográfico. 8. ed. Campinas: Papirus; 2004.

19. Baudrillard J. Simulacros e simulação. Lisboa: Relógio D'água; 1991.

20. Faveret BMS, Mendonça AL S, Coelho ER, Faustino RR. Eros no século XXI: Édipo ou Narciso? Tempo Psicanal [Internet]. 2007 [citado em 2016 out. 12];39:35-50. Disponível em: https://goo.gl/a96xmw

21. Bauman Z. Liquid times: living in an age of uncertainty. Cambridge: Polity; 2006. 
22. Twenge JM, Konrath S, Foster JD, Keith Campbell W, Bushman BJ. Egos inflating over time: a crosstemporal meta-analysis of the narcissistic personality inventory. J Pers. 2008 Aug;76(4):875-902.

23. Twenge JM. The evidence for generation we and against generation me. Emerg Adulthood 2013;1(1):5-10.

24. Lambert KG. Rising rates of depression in today's society: consideration of the roles of effort-based rewards and enhanced resilience in day-to-day functioning. Neurosci Biobehav Rev 2006;30(4):497-510.

25. Lasch C. A cultura do narcisismo: a vida americana numa era de esperanças em declínio. Rio de Janeiro: Imago; 1983.

26. Alloway T, Runac R, Qureshi M, Kemp G. Is Facebook linked to selfishness? Investigating the relationships among social media use, empathy, and narcissism. Soc Netw [Internet]. 2014 [cited 2016 Oct 12];3(3):150-8. doi: http://dx.doi.org/10.4236/sn.2014.33020

27. Wickel TM. Narcissism and social networking sites: the act of taking selfies. Elon J Undergrad Res Commun. 2015;6(1):5-12.

28. Gupta R, Pooja M. Selfie: an infectious gift of IT to modern society. Glob J Res Anal [Internet]. 2016 [cited 2016 Oct 12];5(1):278-80. doi: http://dx.doi.org/10.15373/22778160

29. Orth O. Presentation of selfie: a modern understanding of goffman's self on Instagram [dissertation on the Internet]. Towson: Towson University; 2016 [cited 2017 Jan 12]. Available from: https://goo.gl/zoPx8p

30. Lupinetti VM. Self-presentation and social media: a qualitative examination of the use of instagram by Amateur NPC female figure competitors [dissertation on the Internet]. Washington: San Jose State University; 2015 [cited 2017 Jan 12]. Available from: https://goo.gl/FqiQJz

31. Ruuhonen H. Self-presentation of social identity through pictures in the context of Instagram wellness community [dissertation on the Internet]. Espoo: Aalto University; 2017 [cited 2018 Feb 20]. Available from: https://aaltodoc.aalto.fi/handle/123456789/24579\#

32. Nascimento CM, Próchmo CCSC, Silva LCA. O corpo da mulher contemporânea em revista. Fractal Rev Psicol. 2012;24(2):385-404.

33. Langaro F, Benetti S. Subjetividade contemporânea: narcisismo e estados afetivos em um grupo de adultos jovens. Psicol Clínica. 2014;26(2):197-215.

34. Retallack $\mathrm{H}$, Ringrose J, Lawrence E. "Fuck your body image": teen girls' Twitter and Instagram feminism in and around school. In: Coffey J, Budgeon S, Cahill H, editors. Learning bodies: the body in youth and childhood studies [Internet]. Singapore: Springer Singapore; 2016 [cited 2017 Feb 18]. p. 85-103. doi: https://doi.org/10.1007/978-981-10-0306-6 6

35. Olszanowski M. Feminist self-imaging and Instagram: tactics of circumventing sensorship. Vis Commun $Q$ [Internet]. 2014 Apr 3 [cited 2017 Feb 18];21(2):83-95. doi: https://doi.org/10.1080/15551393.2014.928154

36. Giles D. Constructing identities in cyberspace: The case of eating disorders. Br J Soc Psychol [Internet]. 2006 [cited 2017 Feb 18];45(3):463-77. doi: https://doi.org/10.1348/014466605X53596

37. Pepin G, Endresz N. Facebook, Instagram, Pinterest and co.: body image and social media. J Eat Disord [Internet]. 2015 [cited 2017 Feb 18];3 (Suppl 1):O22. doi: https://doi.org/10.1186/2050-2974-3-S1-O22

38. Aubrey JS. The Impact of sexually objectifying media exposure on negative body emotions and sexual self-perceptions: investigating the mediating role of body self-consciousness. Mass Commun Soc [Internet]. 2007 May [cited 2017 Feb 18];10(1):1-23. doi: https://doi.org/10.1080/15205430709337002

39. Tiggemann M, Zaccardo M. Exercise to be fit, not skinny: the effect of fitspiration imagery on women's body image. Body Image [Internet]. 2015 Sept [cited 2017 Feb 18];15:61-7. doi: https://doi.org/10.1016/j.bodyim.2015.06.003

40. Novaes JV. O intolerável peso da feiúra sobre as mulheres e seus corpos. Rio de Janeiro: Garamond; 2006.

41. Canesqui AM, Garcia RWD, Dies RW. Antropologia e nutrição: um diálogo possível [Internet]. Rio de Janeiro: Editora Fiocruz; 2015 [acesso em 2018 mar. 18]. Disponível em: http://books.scielo.org/id/v6rkd

42. Sullivan R, Sarker A, O'Connor K, Goodin A, Karlsrud M, Gonzalez G. Finding potentially unsafe nutritional supplements from user reviews with topic modeling. Pac Symp Biocomput [Internet]. 2016 [cited 2017 Feb 18];21:528-39. Available from: https://goo.gl/Woua24

43. Agência Nacional de Vigilância Sanitária (BR). Suplementos alimentares: documento de base para discussão regulatória [Internet]. Brasília; 2017 [acesso em 2018 mar. 29]. Disponível em: https://goo.gl/3yhSDf 
44. Onakpoya IJ, Wider B, Pittler MH, Ernst E. Food supplements for body weight reduction: a systematic review of systematic reviews. Obesity [Internet]. 2011 Feb 2 [cited 2018 July 14];19(2): 239-44. doi: https://doi.org/10.1038/oby.2010.185

45. Kulkarni A, Huerto R, Roberto CA, Austin SB. Leveraging corporate social responsibility to improve consumer safety of dietary supplements sold for weight loss and muscle building. Transl Behav Med [Internet]. 2017 [cited 2018 July 14];7(1):92-7. Available from: https://goo.gl/Kw2pgY

46. Pomeranz JL, Barbosa G, Killian C, Austin SB. The dangerous mix of adolescents and dietary supplements for weight loss and muscle building. J Public Heal Manag Pract [Internet]. 2015 [cited 2018 July 14];21(5):496-503. Available from: https://goo.gl/8vfvVg

47. Cohen PA. Hazards of hindsight: monitoring the safety of nutritional supplements. N Engl J Med [Internet]. 2014 Apr 3 [cited 2018 July 14];370(14):1277-80. Available from: https://goo.gl/GHZyNr

48. Li N, Hauser R, Holford T, Zhu Y, Zhang Y, Bassig BA et al. Muscle-building supplement use and increased risk of testicular germ cell cancer in men from Connecticut and Massachusetts. $\mathrm{Br}$ ] Cancer [Internet]. 2015 Mar 31 [cited 2018 July 14];112(7):1247-50. doi: https://doi.org/10.1038/bjc.2015.26

49. Chayka K. Instagram's creepy ads look like posts from your friends. Who are those people drinking beer in a forest at golden hour? The Atlantic [Internet]. 2016 [cited 2016 Oct 30]:1. Available from: https:// goo.gl/kM6VQ]

50. Turow J, King J, Hoofnagle CJ, Bleakley A, Hennessy M. Americans reject tailored advertising and three activities that enable It. SSRN Electron ] [Internet]. 2009 [cited 2016 Oct 30]:1-27. doi: https://dx.doi. org/10.2139/ssrn.1478214

51. Othon R, Coelho M. A influência do self reality show online na apropriação de práticas de alimentação saudável no Instagram. Razon y Palabra Prim Rev Elect América Lat Espec en Comun. 2016;20(3):425-42.

52. Neves M. Gabriela Pugliesi se diz pioneira no Instagram: "Quando comecei, ninguém publicava rotina. Só tinha paisagens". Influenciadora digital analisa mudança de posts, que rendem cifras como 3,5 milhões de seguidores e ganhos de até R\$ 200 mil por mês [Internet]. G1 (Globo.com). 2017 ago. 01 [citado em 2017 dez. 20]: Tecnologia e Games. Disponível em: https://goo.gl/QXvM6d

53. Saldanha FRMSR. Frango com batata doce: uma análise sobre a construção da identidade fitness no Instagram [Trabalho de Conclusão de Curso na Internet]. Brasília: Universidade de Brasília; 2014 [citado em 2017 dez. 20]. Disponível em: http://bdm.unb.br/handle/10483/9366

54. Edmonds A. "Almost invisible scars": medical tourism to Brazil. Signs ] Women Cult Soc [Internet]. 2011 Jan [cited 2016 Oct 30];36(2):297-302. Available from: https://goo.gl/hmcGjd

55. Sibilia P. O pavor da carne: riscos da pureza e do sacrifício no corpo-imagem contemporâneo. Rev FAMECOS [Internet]. 2008 Abr 13 [citado em 2016 out. 29];11(25):68. doi: http://dx.doi. org/10.15448/1980-3729.2004.25.3286

56. Sauerbronn JFR, Tonini KAD, Lodi MDF. Um estudo sobre os significados de consumo associados ao corpo feminino em peças publicitárias de suplementos alimentares. REAd (Porto Alegre) [Internet]. 2011 abr. [citado em 2018 jun. 2];17(1):1-25. doi: http://dx.doi.org/10.1590/S1413-23112011000100001

57. Sabino C, Luz MT, Carvalho MC. O fim da comida: suplementação alimentar e alimentação entre frequentadores assíduos de academias de musculação e fitness do Rio de Janeiro. Hist, Ci, SaúdeManguinhos [Internet]. 2010 jun [citado em 2018 jun. 2];17(2):343-56. doi: http://dx.doi.org/10.1590/ $\underline{\text { S0104-59702010000200005 }}$

58. Markula P. Firm but shapely, fit but sexy, strong but thin: the postmodern aerobicizing female bodies. Sociol Sport ] [Internet]. 1995 Dec [cited 2016 Oct 30];12(4):424-53. doi: https://doi.org/10.1123/ssj.12.4.424

59. Homan K. Athletic-ideal and thin-ideal internalization as prospective predictors of body dissatisfaction, dieting, and compulsive exercise. Body Image [Internet]. 2010 June [cited 2016 Oct 30];7(3):240-5. doi: https://doi.org/10.1016/j.bodyim.2010.02.004

60. Ridgway JL, Clayton RB. Instagram unfiltered: exploring associations of body image satisfaction, Instagram \#selfie posting, and negative romantic relationship outcomes. Cyberpsyc, Behav Soc Netw [Internet]. 2016 Jan [cited 2016 Oct 30]; 19 (1): 2-7. Available from: http://online.liebertpub.com/ doi/10.1089/cyber.2015.0433 
61. Batista G, Rodrigues R. A construção de Identidade na "geração fitness" do Instagram: a representação do eu e do corpo no ciberespaço. Resumos do INTERCOM: Sociedade Brasileira de Estudos Interdisciplinares da Comunicação; $37^{\circ}$ Congresso Brasileiro de Ciências da Comunicação [Internet]. 2014 set. 2-5; Foz do Iguaçu, PR. São Paulo: INTERCOM; [citado em 2015 jun. 23]. Disponível em: http://www.intercom.org.br/sis/2014/resumos/R9-1378-1.pdf

62. Cowas S. Yoga On Instagram: disseminating or destroying traditional yogic principles? Elon J Undergrad Res Commun [Internet]. 2016 [cited 2017 Sept 15];7(1):33-43. Available from: https://goo.gl/GihGQC 